\title{
Administración liberal y corrupción política: el conflicto del Real Co- legio de San Pablo con el Instituto Provincial de Valencia*
}

\author{
Carles Sirera \\ Universitat de Valencia
}

RESUMEN: El presente artículo estudia los colegios reales de internos dentro del sistema educativo liberal decimonónico a partir de un análisis pormenorizado del Real Colegio de San Pablo de Valencia. Mediante el empleo exhaustivo de fuentes documentales conservadas en cinco archivos, se detalla el funcionamiento de este centro educativo para destacar el conflicto surgido a raíz de la tensión entre los intereses personales de Juan Bravo Murillo, que otorgó empleos de importancia a familiares, y las necesidades de una administración eficiente impulsada por Antonio Gil de Zárate. La lucha entre la corrupción política y los nuevos valores asociados al liberalismo en este caso se vinculó, además, a la problemática del modelo de enseñanza media defendida por el Estado: colegios de internos elitistas o institutos de bachillerato abiertos e inclusivos. Este conflicto se resolvió a favor del modelo de bachillerato único en establecimientos abiertos y, tras la Revolución Gloriosa, se suprimió el Real Colegio de San Pablo para terminar con las malas prácticas de su director.

PAlabras Clave: Corrupción política; Colegios reales; Bachillerato; Educación; Juan Bravo Murillo; Antonio Gil de Zárate.

* Este trabajo se incluye dentro del proyecto de investigación fundamental no orientada «Las bases sociales del Estado y la trayectoria de la sociedad civil en la España del siglo XIX, 1840-1880», Referencia HAR2012-36318. Estudio de caso detallado gracias a la extensa documentación relativa al Real Colegio de San Pablo conservada en el Arxiu del Regne de València (ARV), el Archivo General de la Administración (AGA), el Arxiu Històric de l'Institut Lluís Vives (AHILLV) y del Arxiu Històric de la Universitat de València (AHUV). 
Liberal Administration and Political Corruption: The Conflict between Real Colegio de San Pablo and Instituto Provincial of Valencia

ABSTRACT: The present paper examines the Spanish public schools inside the liberal educative system doing a detailed analysis of the Real Colegio de San Pablo of Valencia. The article studies this Real Colegio in order to point out the conflict provoked by political corruption, since Juan Bravo Murillo, a Spanish minister, appointed relatives to direction posts against the desires of Antonio Gil de Zárate, the founder of the Spanish liberal educative system. In this case, the struggle between personal interest of politicians and the necessities of the new and modern administration were related to the problematic issue of the model of high schools established by the State: elitist public schools or open educative institutes without boarding pupils. This conflict ended in favour of the common secondary education in open schools and, after the triumph of the Glorious Revolution in 1868, the Real Colegio de San Pablo was closed to finish with the malpractice of the management.

KeY WORDS: Political Corruption; Public Schools; Secondary Education; Education; Juan Bravo Murillo; Antonio Gil de Zarate.

\section{INTRODUCCIÓN}

El sistema educativo liberal y la enseñanza media en el siglo XIX han recibido una atención desigual por parte de los historiadores españoles. A pesar de las importantes contribuciones de Antonio Viñao, Federico Sanz y Emilio Díaz ${ }^{1}$ sobre el marco legislativo, la realidad diaria de los centros educativos de enseñanza media no ha sido un objeto de estudio preferente y el número de publicaciones a este respecto es imitado $^{2}$. Del mismo modo, el conocimiento disponible sobre los reales colegios de internos es casi inexistente y el conflicto político y pedagógico vivido a mediados del siglo XIX entre estos internados y los institutos provinciales no ha merecido ninguna investigación monográfica, a pesar de tratarse de un tema que envolvió cuestiones de índole política y cultural relacionadas con el modelo ideal de sociedad que el liberalismo aspiraba a construir como el triunfo del mérito individual o la edificación de una administración eficiente e imparcial.

Por esta razón, el presente artículo estudia detalladamente la historia del Real Colegio de internos de San Pablo de Valencia desde su fundación hasta su cierre definitivo en 1868, con el propósito de describir las causas que pro-

1 VIÑAO FRAGO, 1982. SANZ DÍAZ, 1985. DÍAZ DE LA GUARDIA, 1988

2 SÁNCHEZ PASCUA, 1985. RODRÍGUEZ GUERRERO, 2009. SIRERA MIRALLES, 2011 
piciaron la desaparición de estos centros educativos. Si bien el fracaso en la consolidación de una red estatal de colegios de internos paralela a los institutos provinciales puede atribuirse, simplemente, a la debilidad de la administración pública en España y su atraso económico, en este estudio mostramos que la cuestión fue más compleja, ya que los colegios reales demostraron ser incompatibles con los valores que promovía el sistema educativo liberal. En este sentido, la reconstrucción del día a día del internado permite realizar un estudio de caso centrado en los conflictos surgidos durante el proceso de construcción del Estado liberal entre su aspiración de buena gobernanza y la realidad de la práctica política.

\section{LA CREACIÓN DEL SISTEMA EDUCATIVO LIBERAL Y LOS COLEGIOS DE INTERNOS}

El Plan Pidal de 1845 supuso la creación de un marco legal estable que permitió ordenar y jerarquizar los centros educativos fundados de forma dispersa por el territorio nacional desde hacía siglos. Su primera aportación fue aclarar el organigrama institucional que debía sostener la educación pública: la instrucción primaria recaía en los municipios, la enseñanza media en las provincias y las universidades dependían del Gobierno central. Del mismo modo, bautizó, definitivamente, a los establecimientos de enseñanza media como «institutos» y dispuso que hubiese uno por provincia bajo la autoridad académica del rector responsable del distrito universitario. Estos institutos se encargarían de educar a las futuras clases medias rectoras de la nación y eran la principal innovación de los liberales en el sistema educativo.

Asimismo, el decreto estableció una pirámide de comunicación oficial y ejecución de ordenanzas basada en la sucesión siguiente: Ministro de la Gobernación- Director General de Instrucción Pública- Rector- Director de Instituto, que trazaba una esfera de autonomía respecto de los gobernadores civiles y las diputaciones provinciales, aunque estas últimas eran las responsables de cubrir con sus fondos el déficit que los institutos registraban, ya que las tasas de matrícula eran insuficientes para cubrir sus gastos. Estos institutos eran establecimientos abiertos que solo aceptaban estudiantes externos y, por esa razón, era necesario residir en la capital de la provincia o acudir a la enseñanza privada o doméstica, ya que el gobierno no logró impulsar una red nacional de colegios de internos que permitiese acoger a los estudiantes de los pueblos o pensionar a estudiantes de origen humilde. Antonio Gil de Zárate, Director General de Instrucción pública en la práctica desde 1843 hasta 1851, explicaría años después de abandonar su cargo las razones de este fracaso en su libro De la instrucción pública en España, fracaso que él atribuía a la desconfianza que las clases medias tenían hacia este tipo de establecimientos: 
Cuestión es agitada entre muchos, si conviene ó no establecer colegios donde los jóvenes se eduquen léjos de sus padres, y sujetos á una vigilancia y disciplina especial, que contribuya á que su instrucción sea más sólida y perfecta. No falta quien, al considerar los vicios á qué se halla sujeta esta clase de establecimientos, los crea perjudiciales, prefiriendo el sistema de externos; y fundándose en la conocida distinción que existe entre instruir y educar, sostiene que si el Estado puede encargarse de los primero, lo segundo debe quedar exclusivamente confiado á las familias ${ }^{3}$.

En este sentido, Gil de Zárate consideraba que las reminiscencias de la vida claustral y las instituciones educativas del Antiguo Régimen eran el origen de los recelos que provocaban los colegios de internos:

Sabida es la historia de nuestros colegios llamados mayores y menores: casi todos llegaron á ser una sentina de vicios y escándalos: la opinión pública acabó por condenarlos; y antes que las vicisitudes políticas los destruyeran del todo, muchos habían dejado de existir, ó se hallaban ya sin elemento de vida. Posteriormente nadie ha reclamado su restablecimiento, con tanta más razon cuanto que habían llegado á ser patrimonio exclusivo de ciertas clases y familias ${ }^{4}$.

Por el contrario, los intelectuales católicos fueron defensores de los colegios de internos, precisamente, por el grato recuerdo que tenían de las instituciones académicas del Antiguo Régimen. Vicente de la Fuente, justo antes de que se aprobase el Plan Pidal, escribía al respecto que:

Hemos procurado bosquejar al Colegial, como era en aquellos aciagos tiempos en que no había ni libertad ni motines, ni turrón ni patriotismo... Y decimos era, porque este tipo está ya agonizando, y á la vuelta de pocos años el presente artículo podrá servirle de sermón de honras. En unos puntos la falta de rentas los ha reducido á inanición, en otros las juntas, las diputaciones provinciales ó el gobierno les han dado el golpe de gracia; ora para cargar con el santo y limosna, ó bien para improvisar con sus despojos raquíticos institutos, ó mezquinos establecimientos de beneficencia.

Quizá á la vuelta de los años vendrá algún publicista á revelarnos en tono magistral la noticia de que el sistema colegiado es útil para la educación de la juventud, doctrina que en el día es una blasfemia literaria. Entonces se calificará de ostogodos [sic] y jamancios á los reformadores, que no supieron utilizar establecimientos colegiales, que aún subsistián en España, durante el primer tercio de este siglo, y... ¿quién sabe? ¡quizá vuelva la moda de fundar colegios! 5 .

Por lo tanto, la opinión pública ilustrada partidaria del liberalismo desconfiaba de este tipo de colegios. Unos prejuicios que, según Gil de Zárate, se

3 GIL DE ZÁRATE, 1855, II, 143.

4 GIL DE ZÁRATE, 1855, II, 145.

5 RODRÍGUEZ RUBÍ, 1843: 125. 
sumaban al excesivo amor que los padres españoles sentían por sus hijos, de tal forma que no resultaba sencillo hacerles entender que esa separación era necesaria para formar el carácter del joven, porque, si no era alejado de las atenciones y afectos familiares, se acostumbraría a la indolencia. Por otra parte, el gobierno largo de Narváez, con Juan Bravo Murillo al frente del ministerio de Comercio, Instrucción y Obras Públicas, promovería los colegios reales fundados durante el reinado de Carlos III que habían sobrevivido en Granada, Valencia y Córdoba, atendiendo más a sus intereses particulares que a las necesidades de la instrucción pública.

\section{ORIGENES Y DISEÑO INSTITUCIONAL DEL REAL COLEGIO DE SAN PABLO}

El primigenio Colegio de San Pablo fue fundado en 1559 en Valencia por la Compañía de Jesús con el objeto de formar a los jóvenes que quisieran ingresar en la orden. Con el paso de los años, esta institución fue incrementando su patrimonio mediante donaciones de distintos benefactores y, en 1670, los jesuitas organizaron junto al colegio el Seminario de Nobles de San Ignacio para instruir a los hijos de la nobleza titulada. Cuando Carlos III expulsó a los jesuitas, ordenó con sus circulares de 5 de octubre de 1767 y 14 de agosto de 1768 que se emplearan los bienes expropiados para erigir colegios de internos bajo la autoridad del monarca y el Colegio de San Pablo cambió su nombre por el de Real Seminario de Nobles educandos de la Ciudad de Valencia ${ }^{6}$. Sin embargo, durante el reinado de Fernando VII, los jesuitas retomaron el control, aunque en 1835, expulsados nuevamente, el centro volvería a las manos del gobierno, que «puso un Director y catedráticos nombrados por él; mas decayó completamente, y si no se cerró del todo, quedó tan abandonado, que en parte de su local se colocó la Escuela normal de Instrucción primaria» ${ }^{7}$.

Su suerte cambiaría gracias al Plan Pidal, que dispuso que, por ser Valencia sede del distrito universitario, el instituto provincial se ubicase en el mismo edificio de la universidad, mientras que el Real Seminario de Nobles se reconvertiría nuevamente en un Colegio Real que se financiaría con los bienes incautados a las extintas fundaciones religiosas dedicadas a la enseñanza. Por esta razón, Antonio Gil de Zárate pondría a Juan Manuel Calleja, un presbítero con una sólida carrera dedicada a la enseñanza y antiguo colaborador del Gobierno de José Bonaparte ${ }^{8}$, al frente del recién creado Real Colegio de San Pablo. El 5 de julio de 1847 tomó posesión de todas las propiedades

6 CORBÍN FERRER, 1979.

7 GIL DE ZÁRATE, 1855, II, 152.

8 GARCÍA FOLGADO, 2010, 117-132. 
que habían pertenecido a los jesuitas y, días más tarde, se incautó de todos los bienes de otros colegios religiosos que habían sido suprimidos ${ }^{9}$.

Nacía, en consecuencia, un centro de enseñanza que había acumulado todas las rentas y beneficios provenientes de los antiguos establecimientos educativos municipales y eclesiásticos, en detrimento del instituto provincial que se sufragaría con las matrículas de los estudiantes y las partidas que consignase la Diputación. Esta nueva institución contaba con un extenso y diverso patrimonio que, de forma autónoma, debía gestionar para cubrir sus necesidades. A grandes rasgos, tenían propiedades agrícolas distribuidas en 18 municipios e inmuebles urbanos mayoritariamente radicados en Valencia, así como censos de diversa índole.

TABLA 1. Patrimonio del Real Colegio de San Pablo 1855.

\begin{tabular}{|c|c|}
\hline PATRIMONIO & INGRESOS \\
\hline PROPIEDADES AGRÍCOLAS & 59.638,36 Rs. Vn. \\
\hline $\begin{array}{l}\text { - Propiedades: } 84 \\
\text { - Hectáreas huerta: 47,58 } \\
\text { - Hectáreas arroz: } 45,58 \\
\text { - Hectáreas secano: } 26,3\end{array}$ & \\
\hline BIENES INMUEBLES URBANOS & 25.877,98 Rs. Vn. \\
\hline $\begin{array}{l}\text { - Edificios: } 29 \\
\text { - Arrendatarios: } 43\end{array}$ & \\
\hline CENSOS & 7.774,88 Rs. Vn. \\
\hline - Titulares: 16 & \\
\hline TOTAL & 93.291,22 Rs. Vn. \\
\hline
\end{tabular}

Fuente: AHILLV Libro de arrendamientos, inquilinatos y censos, 1849-1856 ESAISLVV nº 174. Rs: reales, Vn: vellón.

Como es obvio, no era fácil recaudar anualmente los 93.291 reales, ya que debía exigirse el pago a 143 arrendatarios que solían demorarse con las cuotas, a pesar de afrontar unos arriendos muy ventajosos. De hecho, la mayoría de arriendos de tierras de huerta o arrozal eran ostensiblemente bajos, un $30 \%$ en comparación con lo que solían cobrar otros propietarios ${ }^{10}$. Tampoco solían revisarse los contratos al alza cuando ocurría un traspaso entre los familiares, aunque los inmuebles urbanos sufrían incrementos que oscilaban entre el 6\% y el $113 \%$ y el único caso de desahucio registrado entre 1849 y 1866 afectó a

9 Seminario de Nobles, ARV, 22-3, 22-4.

10 CALATAYUd, ROMEO, MILLÁN, 1(Madrid, 2000): 79-107. 
un inquilino de la capital. Por otra parte, los ingresos derivados solo de los alquileres de viviendas suponían una cantidad similar a la renta percibida en 1866 por Juan Bautista Janini Valero, el cuadragésimo propietario de la ciudad ${ }^{11}$.

Por lo tanto, se trataba de un valioso patrimonio de origen heterogéneo y difícil de fiscalizar que Juan Manuel Calleja debía poner en orden bajo la atenta mirada de Antonio Gil de Zárate. No obstante, el 19 de noviembre Juan Bravo Murillo sería nombrado ministro de la cartera de Comercio, Instrucción y Obras Públicas, que asumía de Gobernación la Dirección General de Instrucción Pública, organismo que, como comentó su director, perdía su presupuesto propio y pasaba a depender de los fondos que le asignase el ministro ${ }^{12}$. Esta pérdida de independencia se vería agravada por la nueva actitud de Bravo $\mathrm{Mu}-$ rillo, que optaría por intervenir directamente sobre las cuestiones relativas a los reales colegios sin respetar los cauces reglamentarios creados por el propio Gil de Zárate, quien se vería en muchas ocasiones desplazado por su superior. Sirva de ejemplo de estos cambios que, el 28 de diciembre de 1847, Bravo Murillo nombraba a su primo Antonio Santos Bravo vicedirector, capellán del colegio y profesor de Religión y Moral con el sueldo de ocho mil reales ${ }^{13}$.

Es posible que este hecho no tuviese especial trascendencia, pero marcaba una pauta significativa, en cuanto revelaba que Bravo Murillo deseaba mantener a los colegios reales bajo su tutela, de tal forma que podían ser un poderoso instrumento para beneficiar a amigos políticos, mientras que los institutos provinciales dependían jerárquicamente del Rector del distrito universitario. Si para contratar a profesores de instituto Antonio Gil de Zárate había diseñado unas oposiciones públicas que demostraron ser bastante eficaces y transparentes como proceso de selección ${ }^{14}$, Bravo Murillo, por el contrario, optaría por nombrar el 1 de mayo de 1849 a Victoriano Morillas Alonso profesor de Historia y de Lógica en el Real Colegio de San Pablo, a pesar de que ni tenía título académico ni había pasado prueba habilitadora alguna ${ }^{15}$. Su principal mérito había sido estudiar en Madrid jurisprudencia, si bien, una vez obtuvo la plaza en Valencia, decidió tramitar su título de Bachiller en Jurisprudencia en la universidad de esta ciudad ${ }^{16}$.

En este punto, es necesario señalar que Bravo Murillo estaba empezando a asumir responsabilidades en los cargos más elevados del gobierno y que encontró un recurso público del que podía disponer libremente si, precisamente, su diseño institucional no estaba claramente definido y, en consecuencia, era

11 AZAGRA, 1993: 158.

12 GIL DE ZÁRATE, 1855, I, 204.

13 Real Colegio de San Pablo, AHILLV, Correspondencia cuartillas 1847-1850 nº 190, caja 26, legajo 2.

14 SIRERA MIRALLES, 2011: 115-127.

15 Real Colegio de San Pablo, AHILLV, Registro de Nóminas 1867-1868 nº 181.

16 Expedientes de Grado, AHUV, caja 53, legajo 3. 
difícil determinar quién era el superior jerárquico de los colegios reales con capacidad de fiscalización. En teoría, debía ser la Dirección General de Instrucción Pública, pero Bravo Murillo resolvía los trámites directamente, favoreciendo de este modo una gestión personalista en la administración. A más inseguridad jurídica, más poder de decisión propia y más capacidad de influir sobre los demás. Un modo de obrar que, paradójicamente, Bravo Murillo combatiría con posterioridad, aunque, como señala Juan Pro, al principio de su carrera política tuvo que aprender a pivotar entre la buena gobernanza y las prácticas clientelares ${ }^{17}$.

Sin embargo, esta ambivalencia también era necesaria para sustentar una arbitrariedad que recordase a los clientes políticos su posición subordinada y de dependencia con el propósito de que no olvidasen ser agradecidos. Por esta razón, durante el periodo de Bravo Murillo al frente de la instrucción pública no se regularizó la situación de estos establecimientos. El primer reglamento general sobre los centros educativos promulgado el 8 de julio de 1847 por su predecesor, Nicomedes Pastor Díaz, no abordó esta cuestión y durante su mandato fue, probablemente, un tema de discusión soterrada. Por ejemplo, en el boletín oficial de su ministerio se publicó una nota no oficial que defendía que solo el Gobierno podía ser «el jefe superior de estos establecimientos y designar sus directores especiales»y, por lo tanto, debían de quedar al margen de la fiscalización de las juntas inspectoras de instrucción o de los directores de instituto ${ }^{18}$.

Como es lógico, la distancia física que imponía este centralismo no facilitaba la labor de vigilancia, aunque permitía al ministro del ramo inspeccionar a su conveniencia. El 4 de enero de 1848 Juan Manuel Calleja recibía de las manos del Jefe Político de la provincia un oficio del ministro que, con la contundencia de un dictado, le responsabilizaba de los desajustes patrimoniales producidos antes de su nombramiento, le exigía mayor diligencia en el cobro de las rentas de los colonos, que presentara presupuestos más minuciosos y detallados y que, finalmente, aportara prueba documental de todos los gastos de importancia realizados ${ }^{19}$. Una muestra de celo que, en realidad, solo servía para recordar a Juan Manuel Calleja que, después de solo seis meses al frente del colegio, podía ser cesado en cualquier momento en beneficio del vicedirector, es decir, del primo del ministro.

De hecho, este centralismo era del todo inoperante y si en febrero de 1850 Calleja remitía a Gil de Zárate un informe sobre el perfecto funcionamiento

17 PRO RUIZ, 2006: 157-224.

18 BOLETÍN OFICIAL DEL MINISTERIO DE COMERCIO, INSTRUCCIÓN Y OBRAS PÚBLICAS, 1849: 470.

19 Real Colegio de San Pablo, AHILLV, Correspondencia cuartillas 1847-1850 nº 190, caja 26, legajo 2 . 
del colegio, en mayo del mismo año, ante la posibilidad de que la Infanta Doña María Luisa hiciese una visita, el director le trasladaba al Jefe Político que esto sería un «compromiso vergonzante, porque en este establecimiento no hay más que ver que los dormitorios y el comedor. [...] Tengo que servirme para la enseñanza de celditas humildísimas, en las que si caben los alumnos para oír las explicaciones por consiguiente, no estan vestidas como debieran con los obgetos que debieran tener, y esto es causa de que la parte, en que debería lucir el orden, decoro, inteligencia y brillantez, esté careciendo de requisitos absolutamente indispensables $\rangle^{20}$.

Por lo tanto, el dirigismo de Bravo Murillo no garantizaba el correcto funcionamiento de los colegios, sino que suponía condicionarlos a sus intereses personales. Esta práctica de conceder favores a familiares y conocidos, denunciada con el nombre de favoritismo por la Unión Liberal en la década de $1860^{21}$, no correspondería exactamente al clientelismo político clásico de carácter vertical, porque Juan Bravo Murillo no operaba como un mediador entre la administración central y una comunidad sobre la que tenía una preeminencia directa como patrono o notable local ${ }^{22}$. De igual modo, tampoco parece que el nombramiento de estos profesores, cuyas responsabilidades no eran equiparables a las de un oficial del Gobierno Civil u otro representante de la autoridad, tuviese como principal objetivo ejercer la llamada «influencia moral del gobierno». Más bien se trataba de colocar a personas de total confianza para lograr un control directo sobre un recurso público que se emplearía para obtener beneficios particulares mediante el intercambio de favores entre iguales o personas distinguidas. En este sentido, el Real Colegio de San Pablo era especialmente interesante por la posibilidad de conceder becas de gracia a los estudiantes. Por ejemplo, el 14 de enero de 1848, el ministro ordenaba al director que costease los estudios y la manutención de «uno de los dos hijos de Don José Pablo Pérez Seoane juez electo de primera instancia de Mallorca, dejando á elección del referido Don Jose Pablo el designar cuál de sus dos hijos ha de disfrutar de esta gracia» ${ }^{23}$. Práctica que se repetiría en una decena de ocasiones y que en septiembre de 1850 beneficiaría al sobrino del ministro Manuel Bertrán de Lis para disgusto de Gil de Zárate, que denunciaría este proceder en 1855, porque estas ayudas «han solido darse por gracia, y no en verdad á pobres, sino á hijos de personas muy acomodadas» ${ }^{24}$.

20 Real Colegio de San Pablo, AHILLV, Correspondencia cuartillas 1847-1850 nº 190, caja 26, legajo 2.

21 SIERRA, PEÑA, ZURITA, 2013, 442-449.

22 MÁIZ SUÁREZ, 1996, 43-67.

${ }^{23}$ Real Colegio de San Pablo, AHILLV, Correspondencia cuartillas 1847-1850 nº 190, caja 26, legajo 2.

${ }^{24}$ GIL DE ZÁRATE, 1855, II, 157. 
Sin embargo, de este modo se estaba sometiendo al colegio a un dilema irresoluble: si el atractivo social del Real Colegio de San Pablo provenía de su reputación como establecimiento distinguido, cuánto mejor gestionado fuese mayor sería su valor como bien intercambiable, pero, al subordinar la institución a intereses espurios, se impedía dotar al colegio de una normativa clara y objetiva que le diese suficiente seguridad jurídica y mecanismos de rendición de cuentas para garantizar la honestidad de sus directores.

\section{LA SOTERRADA LUCHA BUROCRÁTICA}

Bravo Murillo abandonó la cartera de Comercio por la de Hacienda el 19 de agosto de 1849 y el 25 de septiembre de 1851 Antonio Gil de Zárate lograba promulgar un extenso reglamento con 47 artículos dedicados específicamente a describir cómo debían financiarse los centros educativos y cómo debía realizarse la rendición de cuentas. Del mismo modo, colocó al Real Colegio de San Pablo bajo la autoridad del Rector de la Universidad de Valencia y el 1 de febrero de 1851, comunicaba al director del colegio que:

Con el objeto de disminuir el presupuesto de la provincia de Valencia, en el todo ó en parte de la cantidad señalada en el mismo para contribuir en el sostenimiento del Instituto agregado á la Universidad, se declara éste refundido en el Colegio Real establecido actualmente en el edificio de San Pablo: segundo, el nuevo establecimiento llevará la denominacion de colegio Real é Instituto provincial de segunda enseñanza. [...] Los catedráticos del Instituto lo serán del Colegio Real igualmente, puesto que han de concurrir á unas mismas cátedras los alumnos de ambos establecimientos 25 .

A los pocos meses, Gil de Zárate recordaría nuevamente al director que el patrimonio con el que contaba su centro era suficiente para sufragar sus costes y que con el remanente debía cubrir parte del déficit del instituto provincial ${ }^{26}$. No obstante, el 5 de mayo de 1852 fallecería Juan Manuel Calleja ${ }^{27}$ y su cargo recaería en Antonio Santos Bravo, justo cuando su primo era el Presidente del Consejo de Ministros. En esta tesitura, contestaría que, por problemas administrativos, no era posible acatar estas órdenes. Sus excusas fueron aceptadas por el gobierno y Antonio Santos obtuvo unos meses de prórroga que lograría prolongar durante años. En meses posteriores, desde el ministerio le comunicarían que las cuentas facilitadas por el colegio estaban incompletas y en marzo de

25 Seminario de nobles, ARV, 73-1.

26 Seminario de nobles, ARV, 73-1.

27 BOLETÍN OFICIAL DEL MINISTERIO DE GRACIA Y JUSTICIA, 1852, I, 736. 
1853 incluso le manifestarían abiertamente sus sospechas sobre posibles casos de falsificación de nóminas ${ }^{28}$.

Sin embargo, desde Madrid no se tomaría ninguna medida al respecto y, en última instancia, cundió la tolerancia hacia el comportamiento del nuevo director, que se había negado a acatar la autoridad del rector. Su rebeldía era notable, porque en 1855, durante el Bienio Progresista, decidió ocupar parte de las dependencias asignadas a la Escuela Normal de Maestros, institución con la que compartía edificio ${ }^{29}$. Esto motivó que Joaquín Avendaño, el director de la Escuela Normal, protestase ante su superior, el Rector, quien respaldó sus reclamaciones. Empezó, entonces, una larga lucha burocrática para lograr que Antonio Santos abandonase el espacio usurpado y accediera a contribuir económicamente en las reformas necesarias para restaurar el edificio, un contencioso que implicó al Ayuntamiento, que intentaría sin éxito obligar al director a hacer estas reparaciones por razones de seguridad y salubridad. Como consecuencia de su fracaso, en 1861 el municipio tildaría el aspecto externo de la institución como «un conjunto repugnante» ${ }^{30}$.

Durante este conflicto, el Gobernador Civil se mantuvo al margen y desde el Gobierno solo se intentó en 1856 normalizar parcialmente la financiación del centro gracias a la venta en pública subasta de parte de sus propiedades, cuyo importe se reconvertía en deuda pública a perpetuidad ${ }^{31}$, ya que de este modo se impedía la tutela sin intermediarios sobre el patrimonio y se garantizaba que los ingresos declarados se ajustaran con las rentas percibidas, si bien no se remediaba el problema del empleo fraudulento de esos fondos en gastos no justificados. Desafortunadamente, no es posible saber por qué los progresistas no cesaron a Antonio Santos, si bien es posible que consideraran este conflicto como un tema marginal ante la magnitud de las reformas que debían emprender para combatir las malas prácticas instauradas en la administración. Sea como fuese, cuando los moderados volvieron al poder, la intención de Claudio Moyano fue terminar con los colegios reales y reconvertirlos en simples pensiones anexas a los institutos. El reglamento de 1859 reforzó el modelo de bachillerato uniforme, de tal forma que la enseñanza media se consolidó como un tramo educativo único que no podía ofertarse de forma paralela en los institutos provinciales y en los colegios reales. En consecuencia, el Real Decreto de 6 de noviembre de 1861 dictaminó que los colegios pasasen a estar bajo la autoridad de los directores de instituto, que podrían emplear los fondos de los colegios para facilitar el acceso a la enseñanza en régimen de

28 Seminario de nobles, ARV, 73-3.

29 SÁEZ FERNÁNDEZ, 1986: 54-69.

30 Seminario de nobles, ARV, 73-11.

31 Real Colegio de San Pablo, AHILLV, Libro de arrendamientos, inquilinatos y censos. $1849-1856 \mathrm{~N}^{\circ} 174$. 
internado a los niños de fuera de la capital. Por esta razón, José Gandía, el director del instituto provincial de Valencia, fue comisionado por el Rector para efectuar la reorganización del Colegio Real de San Pablo ${ }^{32}$.

Una vez recibidas estas instrucciones, José Gandía exigió a Antonio Santos un informe detallado sobre el estado del colegio: número de alumnos, gastos presupuestados, personal docente contratado y sus títulos académicos. Al año siguiente, pidió una relación de los bienes bajo su titularidad, así como explicaciones sobre algunos detalles poco claros de los cuentas. Esta proximidad permitía ejercer una presión que, progresivamente, debía laminar la rebeldía de Antonio Santos y, en parte, no tardó en lograr algunos de sus objetivos, porque el rector, en un inusitado gesto de fuerza, despidió a todos los profesores del centro por carecer de la formación requerida y los sustituyó por los catedráticos del instituto, aunque tuvo que respetar a los cargos administrativos al estar su autoridad circunscrita al ámbito académico ${ }^{33}$. Si éste había sido el primer paso, el siguiente era doblegar a los administradores y, con ese propósito, José Gandía preguntó por carta «si existe en ese Colegio Administrador de bienes del mismo; cual es la retribucion que por dicha Administracion tiene, y bajo que condiciones ha obtenido su nombramiento» ${ }^{34}$.

Sin embargo, en esta ocasión sus esfuerzos no fructificarían, porque el director del instituto y el rector carecían de instrumentos legales para destituir a los cargos de responsabilidad administrativa. Inscritos dentro de una esfera de autonomía propia desde el Plan Pidal, donde ejercían poderes disciplinarios de efectos académicos, no podían lidiar con unos hombres ajenos a los claustros de catedráticos, designados directamente desde el gobierno y protegidos por su red de favores personales. Por otro lado, no podía esperarse una actitud valiente, combativa y resuelta de la Junta Inspectora de enseñanza por su naturaleza colegiada, cuyos miembros estaban supeditados a la diputación provincial y los partidos políticos. Solo el Gobernador Civil podía auxiliarles eficazmente en este cometido; pero éste respondía exclusivamente a los deseos de Madrid y, nuevamente, se mantuvo al margen. Si el rector no protestaba con suficiente energía ante la Dirección General de Instrucción Pública como para que ésta, a su vez, presionara al ministro de Fomento para que el Consejo de Ministros decidiera implicarse en la resolución de estas faltas y ordenase al Gobernador Civil intervenir, el director del Real Colegio de San Pablo no se sometería ante el instituto para terminar desapareciendo refundido en el seno de éste. Un conflicto que no afectaba solo al instituto de enseñanza media, sino que también estaba provocando la paralización de la Escuela Normal de Maestros. Al usar la parte del edificio que estaba en ruinas, por razones de

32 Seminario de nobles, ARV, 73-11.

33 Seminario de nobles, ARV, 73-12.

34 Seminario de nobles, ARV, 73-13. 
seguridad tuvieron que abandonar las instalaciones en $1853 \mathrm{y}$, desde entonces, peregrinarían por diversos edificios e incluso afrontarían el cierre de la escuela durante algunos cursos hasta que la Revolución Gloriosa les conferiría la oportunidad de instalarse en una nueva sede ${ }^{35}$.

Por lo tanto, Antonio Santos Bravo, gracias a su parentesco con uno de los políticos más poderosos e influyentes de la corte y de la falta de unas disposiciones claras que dotasen al rector de capacidad de intervención directa sobre su gestión, se aprovechaba de su cargo y del patrimonio puesto a su disposición. En el Real Colegio de San Pablo solo se atendía a la voluntad de su director, mientras que los institutos provinciales debían respetar escrupulosamente la pirámide jerárquica de mando de Rector-Dirección General de Instrucción Pública-Ministro, que servía para hacer efectivas las disposiciones dictadas por los superiores. La enseñanza media había nacido con la pretensión de preparar a las futuras clases medias para la ciudadanía activa y familiarizarlos con valores como la igualdad ante la ley o la libre concurrencia; pero el Real Colegio de San Pablo demostraba que algunos espacios de poder estaban reservados a personas de estatus superior que consideraban que no debían responder ante la autoridad competente. Por esa razón, desde el instituto provincial se pensó que deberían responder ante la opinión pública.

\section{EL PROCESO AL REAL COLEGIO DE SAN PABLO}

La llegada al gobierno de los neocatólicos en 1866 fue una grave amenaza para los institutos provinciales, ya que Manuel Orovio, el ministro de Fomento, tenía la determinación de propiciar su asfixia económica para favorecer a los colegios religiosos y los seminarios conciliares. En su Real Decreto de 9 de octubre de 1866 cambió el sistema de financiación de la enseñanza media para reducir los ingresos de los institutos y el 10 de septiembre de 1866 decretó que los seminarios conciliares, establecimientos más económicos y menos exigentes que los centros públicos, pudiesen conceder el título de bachiller. Todo un conjunto de medidas que, en un breve plazo de tiempo, propiciaría un inmenso déficit en las cuentas de los institutos que las diputaciones serían incapaces de cubrir, de tal forma que se produciría la degradación de estos establecimientos a consecuencia de los recortes presupuestarios.

En Valencia, por ejemplo, los ingresos bajaron en un solo curso un 30\% $(30.000 \text { reales })^{36}$, cifras que alarmaron a su directiva por el futuro que le esperaba a la institución. El director del instituto, el catedrático Miguel Vicente

35 SÁEZ FERNÁNDEZ, 1986: 54-69.

36 MEMORIAS DEL INSTITUTO PROVINCIAL DE 2a ENSEÑANZA,1868:18. 
Almazán, a pesar de ser un reconocido publicista neocatólico y un firme partidario de Manuel Orovio, intentó advertir al rector y a la Dirección General de Instrucción Pública de la situación que se estaba produciendo en el instituto $\mathrm{y}$, ante la falta de respuestas, resolvió que la única forma de garantizar la viabilidad económica del instituto era incautarse del patrimonio del Real Colegio de San Pablo ${ }^{37}$. Por lo tanto, tomó la determinación de hacer cumplir las disposiciones de la Dirección General desobedecidas por Antonio Santos.

El problema, empero, era que Miguel Vicente Almazán no contaba con la autoridad efectiva suficiente como para destituir al presbítero y traspasar la titularidad de los bienes del colegio a nombre del instituto provincial. Por esa razón, consideró oportuno instruir un expediente informativo sobre el funcionamiento interno del colegio que sirviera para forzar el cese de su director. Con este propósito, en noviembre de 1866, Miguel Vicente Almazán mandó llamar al empleado del Real Colegio de San Pablo Joaquín García, de 30 años, para interrogarle sobre el día a día del centro. Además del director, estaban presentes el vicedirector, el historiador Vicente Boix, que era una destacada personalidad pública y un antiguo líder de los demócratas valencianos ${ }^{38}$ y el secretario, Jaime Banús. Sobre el aspecto económico, su declaración confirmó las sospechas que se albergaban desde hacía lustros sobre falsificación de nóminas y suplantación de personalidades: en vez del cocinero que figuraba en los libros de contabilidad, había seis mujeres trabajando en la cocina. Pero, en realidad, esto se trataba de un tema menor ante la relación de inmoralidades de otro tipo que siguieron, cuyo principal protagonista era «don Lorenzo Soto, sobrino del Director interno, inspector $1^{\circ}$ que era del Colegio, [que] hace unos tres años estuvo enfermo de sífilis ó mal venéreo, siendo curado en el mismo establecimiento $\mathrm{y}$ divulgándose la noticia entre los colegiales que pusieron en las paredes rótulos muy indecentes relativos a la enfermedad del mencionado inspector ${ }^{39}$. También era notorio su sistemático absentismo laboral, debido a que simultaneaba esta ocupación con los estudios de magisterio y su afición al juego.

Por su parte, Antonio Santos se desentendía de todos estos problemas, incluso cuando Joaquín «le hizo presente que varios alumnos estaban viciados, y que Tormo segundo pasaba por las noches á la cama de otro Colegial y cohabitaban [porque] del pecado de sodomía tienen noticia varias personas en Valencia pues se ha repetido muchas veces y en distintas ocasiones». Ni tampoco se preocupó al saber que circulaba un cuaderno manuscrito lleno de obscenidades entre los colegiales, aunque sí había intentado disimular sin éxito alguno el embarazo de una cocinera soltera, que no pasó inadvertido ante los ojos de unos púberes especialmente atentos a cualquier referencia que

37 SIRERA MIRALLES, 81 (Madrid, 2011): 241-262.

38 ORTEGA, 1987.

39 Sección 5, Asuntos generales de institutos, AGA, caja 32, legajo 9284. 
tuviese que ver con la sexualidad. Pero, el acontecimiento que más había agitado a los internos fue el siguiente:

Hace cosa de dos meses, se encontraron á la Ayudante de cocina llamada Vicenta, soltera, de diez y ocho años de edad, tendida en el suelo de la cocina y destapada, que dijeron que la había dado un insulto; pero entre los colegiales corrió la voz de que habia sido maltratada por la cocinera á causa de los celos que le daba con ella el mayordomo; que dicha Vicenta murió á las cuatro horas de haberla dado el insulto y su cadáver fué sacado ocultamente, por la puerta de la cochera que da al muro y que solo sirve para salir la tartana, sin entierro ni solemnidad alguna más que el haberse presentado el carruage mortuorio de la empresa de coches fúnebres; y que para sacar el cadáver, se mandaron a recoger á los colegiales para que no oyesen ni viesen nada de lo que ocurría.

Después de este testimonio, hicieron llamar a otro empleado, José Plumer, que ratificó las palabras de su compañero y añadió que «el vicio de sodomía es muy antiguo en el Colegio pero se ha desarrollado en mayor grado en los últimos años» ${ }^{40}$. Asimismo, relató hechos tan graves como que «el inspector tercero, Ricardo Soto sobrino del Sr. Director solicitó con palabras indecentes al Colegial Moraleda de primera enseñanza, escitándole á que hiciera con él actos vergonzosos, á lo que se negó el colegial, o menos delictivos como que el colegial Orts [decía] publicamente que padece gonorrea o purgaciones; y que dicho Orts y Tormo primero, estando en la enfermería, dijeron á Maria enfermera que les pusiera remedios en las partes pudendas».

Los escolares, por su parte, tampoco dudaban en acosar y manosear a las criadas con bastante insolencia y aprovecharse de «Lorenzo el portero segundo [que] casi todos los días se emborracha [y] entra á los Colegiales toda clase de comidas, vino, aguardiente y licores, tabaco y hasta medicinas para males ocultos». Todo este ambiente de corrupción, al que se debía sumar la mala comida que se servía, había propiciado que «el Colegial Marín hoy en el Colegio de San Rafael [saliese] del de San Pablo enfermo de balano por ser muy vicioso; y que el colegial Tormo segundo se [esté] aniquilando diariamente por el abuso de la sensualidad, pues Garrigues le persigue sin descanso».

Posteriormente, se hizo testificar a dos empleados más que confirmaron gran parte de esta versión de los hechos e insistieron en la falta de control y la desidia manifiesta del director respecto de sus subordinados y cualquier otro aspecto relacionado con el régimen interior del establecimiento. La relación de faltas también incluía el maltrato sufrido por dos internos a manos de Lorenzo Soto, el sobrino de Antonio Santos, e incidencias menores como pequeños robos. La primera medida de Almazán fue comisionar a un médico con el objeto de reconocer a los niños que podían estar incurriendo en com-

40 Sección 5, Asuntos generales de institutos, AGA, caja 32, legajo 9284. 
portamientos inmorales para que comprobase cuál era su estado de salud. Como es lógico, si bien sus actos podían ser considerados como indecentes, eso no implicaba necesariamente un deterioro de su organismo. Por esa razón, el doctor contestó con bastante criterio científico que sobre «Antonio Orts [...] solo ha encontrado una mancha de semen en la camisa habiéndole dicho el referido colegial que sentía escozor al tiempo de orinar; [y] que por último ha reconocido tambien á Don Juan Tormo en quien no ha encontrado señal alguna de enfermedad y de quien nada puede afirmar sobre si ha perdido en robustez por no ser conocido anteriormente». En relación con el alumno transferido al Colegio de San Rafael, refirió que al orinar había soltado la piel del prepucio, originándole una pequeña herida que se había infectado. Arreglar el asunto solo requirió de unos baños de agua caliente y «un poco de delicadeza».

A pesar de que las secuelas no revestían gravedad, la información acumulada sobre la negligencia manifiesta de los encargados, el fraude cometido por los gestores, más el licencioso desenfreno consentido, arrojaba un cuadro lo suficientemente escandaloso como para constituirse en un arma eficaz de presión. Tras consultar con el rector y ser felicitado por sus pesquisas, Almazán empezó una campaña de acoso contra Antonio Santos, al mismo tiempo que remitía una copia del expediente por él instruido, con los nombres de los menores afectados censurados, a los juzgados de primera instancia con el fin de que iniciaran el debido proceso.

Probablemente asustado por el cariz que tomaban los acontecimientos, Antonio Santos salió precipitadamente de Valencia y, por haber abandonado su puesto sin haber obtenido una licencia, su cargo recayó provisionalmente en la persona de Vicente Boix. Acto seguido, él y Almazán despidieron a los subalternos vinculados por amistad o parentesco con el anterior director. Asimismo, aprovecharon la ocasión para someter a una mayor intimidación al vicedirector, el capellán proveniente del Escorial Francisco Manuel Navajas, quien intentaba en vano rehuir cualquier contacto con sus inquisidores para no tener que responder a ninguna pregunta. Por el contrario, el administrador de los bienes se negó a colaborar con Almazán, replicándole que él estaba imbuido de los poderes propios de un Mayordomo, ya que no era un simple administrador. Es decir, que tenía bajo fideicomiso personal e intransferible bienes públicos y, por ende, no se veía impelido a presentar cuentas ante nadie. Obviamente, fue destituido, aunque antes escondió todos los libros de contabilidad y la caja de caudales para entorpecer al máximo la labor de sus sucesores ${ }^{41}$.

Después de todo lo sucedido, Vicente Boix promovió un nuevo reglamento interno y fijó las nuevas anualidades que debían abonar los internos ${ }^{42}$,

41 Sección 5, Asuntos generales de institutos, AGA, caja 32, legajo 9284.

42 INSTRUCCIÓN PARA LOS QUE PRETENDAN SER ALUMNOS DEL COLEGIO REAL DE SAN PABLO, 1867. 
mientras que Miguel Vicente Almazán nombró a un hermano suyo administrador del centro. Francisco Manuel Navajas, por su parte, resistió el máximo tiempo posible enrocado en su plaza, pero siempre ausente bajo pretextos como enfermedades y achaques. Harto de sentirse perseguido, dirigió el 28 de marzo de 1867 una carta en petición de auxilio a Manuel Orovio en la que hacía una relación de sus protectores en la corte, denunciaba las coacciones sufridas, sostenía una hiperbólica defensa del trabajo que habían realizado él y Antonio Santos al frente del centro y atacaba sin piedad a Vicente Almazán, a quien acusaba de querer apropiarse de las rentas del colegio y al que se criticaba por no cumplir con su horario lectivo ${ }^{43}$.

No obstante, esta falta de profesionalidad no podía conllevar una pena de tal consideración como para que la Dirección General actuase contra el director de un instituto que, además, era afín ideológicamente. Por otro lado, Antonio Santos fue más inteligente y, en su misiva del 17 de abril, supo cómo hacer caer en desgracia a Almazán: rebatió su proceder por haber declarado «una guerra tan encarnizada como pocas se habrán visto; pues ha llevado a todos los terrenos donde más perjudicial y sensible pudieran serle los ataques. Ante el público; ante los tribunales de justicia, y ante el Gobierno, le ha presentado como criminal y como hombre mas inmoral y estúpido del mundo». Con un preclaro olfato político, Antonio Santos se escandalizaba porque Almazán había presentado su expediente «al juzgado del distrito, como si a la autoridad judicial le tocara conocer las faltas de un empleado público antes de que el Gobierno se entere de dichas faltas». Es decir, se había erigido como un empleado público responsable e independiente que se atrevía a denunciar de oficio un palmario caso de corrupción y amiguismo, que perturbaba el correcto funcionamiento de la administración y atentaba contra su crédito y decoro. Como sostenía Antonio Santos, Miguel Vicente Almazán «por haber formado por sí y ante sí, sin conocimiento de la autoridad competente, un espediente de faltas [y] por haber llevado dicho espediente a los tribunales de justicia sin conocimiento del Gobierno $\rangle^{44}$ merecía ser cesado de inmediato.

A raíz de esta nota de alerta, la Dirección General pidió que le enviasen todos los originales de dicho expediente y que no se facilitara ningún documento a nadie más. Almazán, empero, ya había enviado copia de los primeros interrogatorios a los tribunales, aunque estos estimaron que no había motivos para actuar judicialmente contra ninguno de los implicados. No sabemos si ayudó a desequilibrar la balanza en favor de Antonio Santos Bravo, pero, junto a todos los papeles referidos a este caso que se conservan en el Archivo General de la Administración, hay una carta dirigida a Juan Bravo Murillo por un tal Fernando Ferrer con la pretensión de convencerle de que su primo

43 Sección 5, Asuntos generales de institutos, AGA, caja 32, legajo 9284.

44 Sección 5, Asuntos generales de institutos, AGA, caja 32, legajo 9284. 
era un hombre honesto y que Vicente Almazán era un espíritu pérfido que debía ser trasladado a otro instituto. Fuese como fuera, el 28 de enero de 1868 Antonio Santos se presentó en la ciudad para retomar sus responsabilidades y, a pesar de la oposición de Vicente Boix y el rector, el 25 de febrero el ministro de Fomento y la Dirección General de Instrucción Pública ratificaron a Antonio Santos en su antiguo destino45. A su vez, Vicente Almazán renunció a su cargo «por razones de decoro, motivadas por causas siempre dolorosas y estrañas á este lugar, [que] le fueron consideradas por la Superioridad para la aceptacion de la terminacion de su cargo» ${ }^{46}$.

Por lo tanto, Manuel Orovio, quien había tenido una carrera política paralela a la de Bravo Murillo ${ }^{47}$, no dudó en restituir a un presbítero desacreditado y hacer caer a un director afín a su corriente ideológica, antes que depurar las responsabilidades de sus subordinados. Es obvio que el temor al escrutinio de la opinión pública en un momento de agitación política justificaba tolerar cualquier tipo de ineptitudes y mezquindades. Sin embargo, las órdenes ministeriales no siempre eran suficientes para detener la indignación con el gobierno. Es difícil calibrar cómo influyó el escándalo del Real Colegio de San Pablo en el descrédito de la monarquía reinante en Valencia; pero, tras el triunfo la Revolución Gloriosa, el rector de la Universidad de Valencia y la Junta Revolucionaria decretaron en noviembre de 1868 la supresión del Real Colegio de San Pablo y la incorporación de su patrimonio al instituto provincial. Dicha medida la explicaron del siguiente modo a Ruiz Zorrilla, ministro de Fomento:

Pero si el carácter del Colegio de San Pablo estaba ya bien definido, nunca se ha regularizado su administración de una manera conforme con su nuevo estado. [...] Administrabanse sus rentas de manera irregular hasta el punto de que la Junta provincial inspectora del Colegio no ha aprobado cuenta alguna de las que trimestralmente se rendían; y esta anormal organización debía producir y en efecto produjo censurables abusos.

En vano para remediarlo se dirigió repetidas veces al Ministerio de Fomento la Junta inspectora en comunicaciones que ni aún lograron contestación. Igualmente infructuosas fueron las reclamaciones del Director del Instituto D. José Gandia [...]. Lo más grave de todo fué el expediente instruido en Diciembre de 1866 por el Director del Instituto D. Miguel Vicente Almazán; expediente que se remitió á ese Ministerio en virtud de orden telegráfica. [...] Y bien es verdad que el Juzgado, á quien se pasaron las diligencias instruidas, no halló méritos para proceder criminalmente, no es menos cierto que al simple anuncio de la accion de los tribunales, el Director delegado se alejó de esta ciudad repentinamente y sin licencia, prolongando por largo tiempo su ausencia. Por otra parte, el sobreseimiento criminal de-

45 Enseñanza Media, AHUV, caja 3, legajo 2.

46 MEMORIAS DEL INSTITUTO PROVINCIAL DE 2a ENSEÑANZA, 1868: 10.

47 CAPELLÁN DE MIGUEL, GÓMEZ OCHOA, 2003. 
jaba en pie los abusos administrativos, y no era posible dejar de reprimirlos sin hacerse cómplice de ellos ${ }^{48}$.

La Junta Revolucionaria y el rector comisionaron a Vicente Boix, nuevo director del instituto, para que incautase todos los bienes y rentas del colegio. Los recibió personalmente de manos de Antonio Santos, quien no tuvo reparos en confesar que no había ni un céntimo en la caja de caudales y que no sabía con certeza si había perdido algún título de deuda pública ${ }^{49}$. La recuperación de este patrimonio permitió que el instituto dejara de compartir sede con la universidad y se trasladara a un monumental edificio que, en esta ocasión, sí fue restaurado empleando recursos propios. Del mismo modo, las rentas ganadas se emplearon para sufragar nuevas enseñanzas técnicas como el peritaje mecánico, el químico y el náutico, además de fundar una Escuela Industrial de Artesanos completamente gratuita y sostener una escuela de primaria anexa al instituto ${ }^{50}$. La Revolución Gloriosa supuso tanto el restablecimiento de la ley como un fuerte impulso de la enseñanza media en la provincia de Valencia, porque se recuperó un patrimonio secuestrado por unos sacerdotes que, en su concepción patrimonialista de la administración, se sentían libres de responder ante nadie de sus actos.

\section{UNA NUEVA ADMINISTRACIÓN FRENTE A UNA NUEVA CORRUPCIÓN}

Como es obvio, este duro enfrentamiento vivido entre las dos entidades no respondía exclusivamente a desavenencias personales o intereses hacendísticos. El conflicto latente entre el Real Colegio de San Pablo y su director con el instituto provincial era la lucha entre los partidarios de las nuevas instituciones liberales que debían garantizar la igualdad ante la ley y el control del gobierno y los oportunistas que habían promocionado socialmente gracias al patronazgo político y que, con el fin de consolidar su nuevo estatus, ansiaban volver al mundo afectivo e intelectual del Antiguo Régimen. La resistencia y el descaro del presbítero Antonio Santos se explican porque, aferrado a sus influencias, aspiraba a vivir cómodamente en una sociedad donde los extintos privilegios jurídicos se hubiesen reconvertido en unas nuevas garantías de inmunidad para las familias vinculadas al Gobierno y la Iglesia, cuyo ejercicio de la autoridad debía estar blindado frente al escrutinio de la opinión pública. Por lo tanto, los centros educativos sostenidos por el Estado, en vez de formar a futuros ciudadanos preparados para hacer progresar a la Nación,

48 Sección 5, Asuntos generales de institutos, AGA, caja 32, legajo 9284.

49 Seminario de Nobles, ARV, 3-18.

50 SIRERA MIRALLES, 2011: 103-114. 
debían reforzar e inculcar un espíritu de casta a los hijos de las elites administrativas. En esa pretensión, Francisco Manuel Navajas hacía esta descripción ideal del Real Colegio de San Pablo a Manuel Orovio para acallar las críticas suscitadas por la investigación de Almazán:

Cada día, cada hora y cada momento, lo mismo en clase que fuera de ella, se inculca constantemente á los alumnos los deberes que tienen para con Dios, para consigo mismos y para con todas las guerarquías [sic] de la sociedad ó individuos de la especie humana; en un Colegio, digo, donde al salir los niños lavados y aseados de los dormitorios, la primera operación que ejecutan todos reunidos es la oración de la mañana; pasan después una hora en la sala de estudios, enseguida asisten á misa, y ocupan el resto de la misma en desayuno, clase y horas de estudio; que durante la comida se les tiene lectura acerca de los deberes del hombre y reglas de urbanidad; que terminada la comida tienen una hora de juego ó se ejercitan en las clases de gimnasia, esgrima ó equitación segun les corresponda; que concluidos estos egercicios vuelven uno [sic], que á las siete vuelven á estudio donde permanecen hasta las ocho y cuarto, á cuya hora rezan el rosario; que mientras la cena se les tiene lectura sobre la misma materia que al medio día, ó de historia sagrada; que antes de pasar á los dormitorios hacen en corporación la oración de la noche, $[\ldots]$ los domingos se les esplica el Evangelio y se les enseñan los preservativos para no caer en el pecado y á practicar alguna de las virtudes; [...] todo lo referido es ciertísimo, y nadie lo podrá contrariar: en un Establecimiento con las condiciones referidas podrá haber alguna falta en algún individuo (pues hasta en los elegidos por Jesucristo las hubo), pero no se podrá decir que hay inmoralidad ó desmoralización ${ }^{51}$.

Este relato, empero, era más bien una prueba del alejamiento de la realidad que sufrían hombres como este monje proveniente del Escorial. En su defensa, el aprendizaje de los contenidos curriculares no merecía siquiera mencionarse, porque la oración y la práctica religiosa en comunión eran el único pilar de una enseñanza adornada con el baile, la esgrima, la gimnasia o la equitación que, además, eran fantasiosos recursos estilísticos, porque no hay indicios de que estas distinguidas actividades se practicasen en el colegio.

Por el contrario, el instituto provincial con su teórico trato igualitario al alumnado, independientemente de la procedencia social de los estudiantes, y su práctica de exámenes públicos e individuales para garantizar que se reconociera el mérito, se transformaba en el estandarte de valores liberales como el orden, la igualdad, la transparencia y la sujeción a la ley. Antonio Santos era consciente de esta contradicción y, en una exposición que envió a la reina el 11 de julio de 1867, describía del siguiente modo el avatar histórico de los colegios reales:

En el año 1847 creó los colegios reales con el fin de que sustituyeran á los suprimidos Seminarios de Nobles y aún les aventajaran en cuanto fuese posible. [...]

51 Sección 5, Asuntos generales de institutos, AGA, caja 32, legajo 9284. 
La Ley de 1861 creó los Colegios provinciales agregados a los institutos y redujo a los Colegios Reales á la condición de aquellos y desde entonces data la decadencia del referido colegio. Y es la razón que los Colegios Reales tenían otra misión que cumplir que los Colegios agregados á los Institutos. Estos respondian á una necesidad creada por la pasada Ley de instrucción pública que arrancaba a los niños del hogar doméstico a una edad muy tierna y en siendo el Colegio la casa de huéspedes vigilada por el director del Instituto, su misión quedaba totalmente cumplida; pero los Colegios Reales debían satisfacer todas las aspiraciones de la época y todas las exigencias de la sociedad más culta y claro es que, reducidos cómo quedaban á meros Establecimientos de pensión con alguna vigilancia no podían llenar su primitivo cometido, y no llenándolo, tenían con precisión que decaer á no darles en su nueva forma condiciones que pudieran hacerlos importantes bajo otros conceptos ${ }^{52}$.

En consecuencia, proponía separar el colegio y todos su bienes del resto de instituciones educativas y «el restablecimiento de las clases de música, baile y florete con la esperanza de que con esta medida concurrirían al Colegio hasta los hijos de las familias distinguidas, pues sabido es que estas no se contentan con una educación común, sino que la quieren tan variada y completa como la que se daba en el mismo Colegio antes de la supresión de las clases de adorno citadas». Se trataba de impulsar unos establecimientos públicos exclusivos para la formación de las elites con la esperanza de reconstruir el esplendor de un ideal aristocrático amenazado por la existencia de un bachillerato uniforme dirigido a formar a una clase media homogénea y sustentadora de la Nación. El sueño de Antonio Santos pretendía institucionalizar mecanismos de cooptación entre las mejores familias para asegurar, de ese modo, su concepto de buen gobierno, aunque, en realidad, evidenciaba la ineficiencia y corrupción que los sistemas políticos oligárquicos y cerrados producen.

Sin embargo, el principal responsable de que el Real Colegio de San Pablo no hubiese ofrecido una educación distinguida y elevada fue, precisamente, su director, que se había aprovechado de sus cargos para emplear los recursos del colegio en su beneficio personal y no para engrandecer a la institución. Su filosofía pedagógica era que la transmisión de conocimientos no era tan relevante como la equitación y la esgrima, porque el objetivo último debía ser resaltar una periclitada noción de autoridad fundada en apellidos de hombres públicos prominentes: el colegio debía exteriorizar el supuesto abolengo atribuido durante siglos a la institución y, por ende, a sus propios internos.

Por el contrario, las condiciones materiales del establecimiento siempre fueron precarias y el director se negó a emplear los fondos propios en su mejora. Por esta razón, es lógico pensar que, a pesar de que el anhelo de distinción elitista siempre ha sido un poderoso reclamo para los padres, el Real Colegio de San Pablo no fue capaz de atraer a las familias más distinguidas

52 Sección 5, Asuntos generales de institutos, AGA, caja 32, legajo 9284. 
de la ciudad. Esto se puede comprobar gracias al estudio de los expedientes de los 137 estudiantes que hubo ingresados durante la década de 1850, que ha permitido hallar 70 partidas de bautismo con referencias a la ocupación paterna, cuyos agregados estadísticos se muestran en la Tabla II.

TABLA II. Profesiones paternas de los internos del rcsp 1850-59

\begin{tabular}{|l|c|}
\hline PROFESIONES & PORCENTAJE \\
\hline Oficial del Ejército & $15,71 \%$ \\
\hline Abogado & $15,71 \%$ \\
\hline Comerciante & $15,71 \%$ \\
\hline Propietario-Rentista & $12,84 \%$ \\
\hline Labrador & $9,98 \%$ \\
\hline Empleado & $5,71 \%$ \\
\hline Noble & $4,28 \%$ \\
\hline Juez & $2,85 \%$ \\
\hline Alcalde & $2,85 \%$ \\
\hline Catedrático & $2,85 \%$ \\
\hline Impresor & $1,42 \%$ \\
\hline Médico & $1,42 \%$ \\
\hline Agrimensor & $1,42 \%$ \\
\hline Maestro de Obras & $1,42 \%$ \\
\hline Jornalero & $1,42 \%$ \\
\hline Barbero & $1,42 \%$ \\
\hline
\end{tabular}

Fuente: ARV Seminario de Nobles 68-1

En términos generales, la composición social del alumnado era más selecta que la del instituto provincial, porque no había hijos de trabajadores urbanos vinculados al mundo de la industria, cuando en el instituto público este grupo suponía más de un $15 \%$ del alumnado ${ }^{53}$. Por otra parte, la casi total ausencia de médicos probablemente se debía a sus prevenciones higiénicas respecto del cenobitismo, mientras que los oficiales del ejército considerarían a un internado como una institución académica acorde con los valores de disciplina, jerarquía, uniformidad, aislamiento y camaradería propios de la vida cuartelaria.

Sin embargo, la presencia de oficiales del ejército o abogados entre las profesiones paternas no implica que el objetivo de distinción y grandeza se cumpliese, porque, como ya se ha señalado, había un desajuste entre las ex-

53 SIRERA MIRALLES, 2011: 61-78. 
pectativas y la realidad. A los futuros alumnos se les hacía saber que las clases de inglés, dibujo natural, equitación, gimnasia y esgrima eran unas actividades opcionales que se pagaban por separado, variando su precio entre los 20 o los 40 reales mensuales. Además, es muy probable que nunca fueran solicitadas, ya que todo el material de esgrima que albergó el colegio en su sala de armas fue un banco de madera y dos guantes ${ }^{54}$; es decir, el resto del equipo (armas, petos y caretas) lo facilitaban los propios alumnos o, evidentemente, nadie practicaba la esgrima en ese centro. De igual modo, resulta difícil determinar cómo se ejercitaban los internos en el arte ecuestre, porque en toda la documentación estudiada relativa al colegio no se ha encontrado referencia alguna a un picadero, establo o caballos a disposición del centro. Además, la ciudad de Valencia destacó, precisamente, por la falta de interés de la nobleza y las familias más distinguidas en practicar la equitación a lo largo del siglo XIX ${ }^{55}$.

Esto contrastaba con el coste anual de la pensión completa, que era de 2.920 reales e incluía el uniforme, prendas de ropa interior, cama, sábanas, utensilios personales y la manutención; mientras que ser medio pensionista implicaba abonar 1.296 reales, aunque solo se tenía derecho a una comida y un uniforme, y se debía entrar en el establecimiento a las ocho de la mañana y salir a las ocho de la noche ${ }^{56}$. El problema era que, además, todos los alumnos se veían sometidos a distintas tasas y arbitrios por servicios como la lavandería, el uso de libros o las comidas especiales que hacían más sangrante el día a día de unos pupilos arrojados a una triste mezquindad. Por lo tanto, no debe sorprender que, a pesar de contar con la presencia del hijo del conde de Zanoni, el colegio no tuviese entre sus matriculados a los descendientes de los apellidos más ilustres de la ciudad de Valencia. De hecho, casi el $80 \%$ de sus estudiantes eran niños provenientes de otras localidades que buscaban en el centro, principalmente, una casa-pensión, mientras que el resto de internos estudiaba allí, probablemente, por el convencimiento que tendrían los padres de que matricular a sus hijos en un colegio real les confería un mayor estatus.

Por lo tanto, es evidente que la inmunidad disfrutada por Antonio Santos solo había servido para despreocuparse de los internos y hacer un mal uso del patrimonio que debía custodiar. En consecuencia, la única forma de garantizar que estuviera a la altura de sus responsabilidades era permitir la fiscalización de su labor, porque, como sostenía el credo liberal, el privilegio solo engendraba corrupción e indolencia.

54 Real Colegio de San Pablo, AHILLV, Inventario General № 182.

55 SIRERA MIRALLES, 2008: 45-59.

56 INSTRUCCIÓN PARA LOS QUE PRETENDAN SER ALUMNOS DEL COLEGIO REAL DE SAN PABLO DE VALENCIA, 1855. 


\section{CONCLUSIONES}

El sistema educativo liberal impulsado por el Plan Pidal supuso una completa ruptura con la tradición escolástica del Antiguo Régimen. Esta cesura respondía a un cambio de valores protagonizado por los sectores liberales que optaron, mayoritariamente, por una enseñanza media única en establecimientos abiertos. Del mismo modo, los gobiernos moderados tampoco consolidaron una red educativa paralela de internados elitistas frente a los institutos provinciales. Si bien es posible que este fracaso se explique en parte por el apoyo mayoritario que neocatólicos como Manuel Orovio ofrecieron a los seminarios conciliares. Entre estos dos frentes, los reales colegios no lograron ser más reputados que los institutos provinciales entre las clases medias, mientras que los enemigos del estado liberal prefirieron impulsar los centros tradicionales que dependían exclusivamente de la Iglesia como los seminarios conciliares.

No obstante, estos intentos fueron vanos y el bachillerato liberal fue el modelo educativo oficial e incontestable. La revolución liberal tuvo tanta amplitud que los modelos educativos y los valores asociados a él cambiaron radicalmente. Por esta razón, no parece posible sostener que la revolución liberal solo tuvo un carácter jurídico, mientras que los comportamientos privados se mantuvieron incólumes, porque las elites políticas del país buscaron un sistema educativo que promocionase la igualdad, el mérito y la concurrencia competitiva en un espacio público a imitación del modelo de la economía de mercado.

A este respecto, se debe señalar que se ha realizado una interpretación equivocada de fenómenos como el patronazgo y el clientelismo ${ }^{57}$. Partiendo de la caracterización de la Old corruption hecha por W.D. Rubinstein como una práctica irracional y premoderna en un concepto weberiano ${ }^{58}$, Cruz sostenía que la endogamia de la elites madrileñas y sus mecanismos de cooptación demostraban que el liberalismo solo había tenido un efecto cosmético sobre la sociedad española. El problema, empero, es que, como hemos expuesto en este artículo, la posibilidad de crear un sistema educativo elitista reservado a las elites del país desde el gobierno no contó jamás con el apoyo de los moderados. De igual modo, parece que la opinión pública fue contraria a los internados y se prefirieron los establecimientos educativos abiertos que, en el caso de Valencia por ejemplo, fueron inclusivos socialmente. En España, las clases medias tuvieron a su disposición un modelo único de instituto con planes de estudio uniformes, porque dentro de la comunidad de ciudadanos activos que debía conformar la parte útil de la Nación no se podía permitir la existencia de elites cerradas que pervirtiesen su teórica igualdad.

57 CRUZ, 1996.

58 RUBINSTEIN, 101/1 (Oxford, 1983): 55-86. 
Por otra parte, la corrupción analizada en este artículo cuestiona el planteamiento de Rubinstein, porque el patronazgo no era más que clientelismo político para lograr el apoyo social necesario para permanecer en el poder. Como señaló Philip Harling, la Old corruption no fue tanto un fenómeno propio del Antiguo Régimen, como la consecuencia de la expansión del presupuesto estatal y la deuda pública durante las guerras napoleónicas ${ }^{59}$. Fue el crecimiento del Estado y las necesidades políticas provocadas para gestionarlo las que extendieron el clientelismo y el patronazgo en Inglaterra y, de forma paralela, favorecieron la corrupción y el empleo de recursos públicos para satisfacer intereses privados. La corrupción fue una derivada de la modernización que despertó las críticas y las denuncias públicas de los radicales por la injusticia del sistema político. Fueron los intentos de ampliar la participación política que motivaron las reformas electorales de la década de 1830 en Inglaterra la principal razón que forzó al gobierno a combatir la corrupción e intentar el establecimiento de una administración eficiente y justa. Por lo tanto, se podría afirmar que la corrupción no fue suprimida por la modernización, sino por los intentos de democratizar el sistema político.

Un caso paralelo es el aquí estudiado, ya que el Real Colegio de San Pablo no era una institución heredada del Antiguo Régimen, sino un invento institucional promovido por Juan Bravo Murillo para recompensar a familiares y amigos políticos. No obstante, esto entraba en contradicción con la reforma educativa de Gil de Zárate, si bien el conflicto entre la autoridad política representada en el ministro y el ideal de eficiencia y justicia perseguido por el funcionario Gil de Zárate no pudo resolverse hasta el triunfo de la primera revolución democrática. Paradójicamente, la actuación honesta y proba de un funcionario como Miguel Vicente Almazán, que era un neocatólico, desató un conflicto que, de algún modo, intentó sin éxito poner fin a la contradicción irresoluble entre los intereses de los miembros del gobierno y las necesidades administrativas. Finalmente, fue la movilización política popular en pos de la democracia la que permitió erradicar el nepotismo sostenido por algunos miembros de las elites políticas y no la modernización administrativa o económica, ya que los burócratas jamás tuvieron una autoridad superior a la de los políticos.

\section{BibLIOGRAFÍA}

Azagra, Joaquín, Propiedad inmueble y crecimiento urbano. Valencia 18001921, Madrid, Síntesis, 1993.

Boletín oficial del Ministerio de Comercio, Instrucción y Obras públicas, Tomo V, Madrid, Imprenta de la Publicidad, 1849.

59 HARLING, 147/1 (Oxford, 1995): 127-158. 
Boletín oficial del Ministerio de Gracia y Justicia, tomo I, Madrid, Imprenta de don José María Alonso, 1852.

Calatayud, Salvador, Romeo, María Cruz, Millán, Jesús, «El rentismo nobiliario en la agricultura valenciana del siglo XIX», Revista de Historia Económica, Año XVIII, 2000, 1, 79-107.

Capellán de Miguel, Gonzalo, Gómez Ochoa, Fidel, El marqués de Orovio y el conservadurismo liberal español del siglo XIX: una biografía política, Logroño, Instituto de Estudios Riojanos, 2003.

Corbín Ferrer, Juan Luis, Monografía histórica del Instituto de Enseñanza media «Luis Vives» de Valencia, Valencia, Ayuntamiento de Valencia, 1979.

Cruz, Jesús, Gentlemen, Bourgeois, and Revolutionaries: Political Change and Cultural Persistence among the Spanish Dominant Groups, 1750-1850, Cambridge University Press, 1996.

Díaz de la Guardia, Emilio, Evolución y desarrollo de la Enseñanza Media en España de 1875 a 1930. Un conflicto político-pedagógico, Madrid, MEC, 1988.

García Folgado, María José, «Juan Manuel Calleja y la enseñanza de la gramática española en Bilbao (1818)», en Gómez Seibane, Sara y Ramírez Luengo, José L. (comp.), Maestra en mucho. Estudios filológicos en homenaje a Carmen Isasi Martínez, Buenos Aires, Voces del Sur, 2010.

Gil de Zárate, Antonio, De la Instrucción Pública en España. Tomo I. Madrid, Imprenta del Colegio de Sordomudos, 1855, [Ed. Facsímil: Oviedo, Pentalfa, 1995].

Gil de Zárate, Antonio, De la Instrucción Pública en España. Tomo II. Madrid, Imprenta del Colegio de Sordomudos, 1855 [Ed. Facsímil: Oviedo, Pentalfa, 1995].

Harling, Philip, «Rethinking «Old Corruption», Past and Present (1995), 147 (1), 127-158.

Instrucción para los que pretendan ser alumnos del Colegio Real de San Pablo de Valencia, Valencia, Imp. de J. Ferrer de Orga, 1855.

Instrucción para los que pretendan ser alumnos del Colegio Real de San Pablo agregado al Instituto Provincial de Valencia, Valencia, Imp. de J. Doménech, 1867.

Máiz Suárez, Ramón, «Estrategias e institución: el análisis de las dimensiones macro del clientelismo político», en Robles Egea, Antonio (Comp.), Política en penumbra. Patronazgo y clientelismo políticos en la España contemporánea, Madrid, Siglo Veintiuno, 1996.

Memorias del Instituto Provincial de $2^{a}$ Enseñanza. Curso de 1867 a 1868 , Valencia, Imprenta de José Rius, 1868.

Ortega, Eduardo, Vicent Boix, València, Institució Alfons el Magnànim, 1987.

Pro Ruiz, Juan, Bravo Murillo. Política de orden en la España liberal, Madrid, Síntesis, 2006. 
Rodríguez Guerrero, Carmen, El Instituto del Cardenal Cisneros de Madrid (1845-1877), Madrid, Consejo Superior de Investigaciones Científicas, 2009.

Rodríguez Rubí, Tomás et alii, Los españoles pintados por sí mismos, Madrid, Boix, 1843 [Ed. Facsímil: Visor Libros, 2002].

Rubinstein, W.D., «The End of «Old corruption» in Britain 1780-1860», Past and Present (1983) 101(1), 55-86

Sáez Fernández, Teodoro, La Escuela Normal de Maestros de Valencia. Monografia histórica (1845-1870), Valencia, Universitat de València, 1986.

Sánchez Pascua, Felicidad, El Instituto de Segunda Enseñanza de Badajoz en el siglo XIX, Badajoz, Diputación Provincial de Badajoz, 1985.

Sanz Díaz, Federico, La Segunda Enseñanza Oficial en el Siglo XIX, Madrid, MEC, 1985.

Sierra, María, Peña, María Antonia, Zurita, Rafael, Elegidos y elegibles: la representación parlamentaria en la cultura del liberalismo, Madrid, Marcial Pons, 2013.

Sirera Miralles, Carles, Cuando el fútbol no era el rey. Los deportes en el espacio público de la ciudad de Valencia (1875-1909), Valencia, PUV, 2008.

Sirera Miralles, Carles, «Neocatolicismo y darwinismo en las aulas: el caso del instituto provincial de Valencia», Ayer, 81, 2011; 241-262.

Sirera Miralles, Carles. Un título para las clases medias: el Instituto de Bachillerato Lluís Vives de Valencia (1859-1902), Valencia, PUV, 2011

Viñao Frago, Antonio, Política y educación en los orígenes de la España contemporánea, Madrid, Siglo XXI, 1982.

Recibido: $14 / 02 / 2013$

Aceptado: 08/04/2014 